Isabel Aninat, Verónica Figueroa y Ricardo González (editores), El pueblo mapuche en el siglo XXI. Propuestas para un nuevo entendimiento entre culturas en Chile (Santiago: Centro de Estudios Públicos, 2017).

RESEÑA

\title{
IDENTIDAD MAPUCHE EN TIEMPOS DE URBANIZACIÓN
}

\author{
Eduardo Valenzuela \\ Universidad Católica de Chile \\ Daniela Aranis \\ Universidad Católica de Chile
}

3 ajo el título El pueblo mapuche en el siglo XXI, el Centro de Estuacerca de la situación del pueblo mapuche, muchos de los cuales están basados en evidencia recogida por el mismo centro en su encuesta "Los mapuches rurales y urbanos hoy". ¿Cuáles son efectivamente los cambios más importantes que enfrenta el pueblo mapuche de cara al siglo XXI? El artículo de Imilan (2017) en este mismo volumen analiza un aspecto crucial respecto de la creciente urbanización de la población mapuche y de las posibilidades de mantener la identidad étnica en un contexto urbano. La proporción de población mapuche que reside en zonas urbanas ha cambiado dramáticamente en las últimas décadas, tal como se aprecia con datos de la serie Casen (2015): en 1996 sólo el 46 por ciento de quienes se identificaron como mapuches residía en un sector urbano, pero veinte años después esta proporción se había elevado a 73 por ciento. En la misma Región de La Araucanía, la población mapuche urbana se ha doblado en igual período, para alcanzar una cifra de

Eduardo Valenzuela. Sociólogo. Académico del Instituto de Sociología y director del Centro de Estudios Interculturales e Indígenas, Pontificia Universidad Católica de Chile. Email: evalenzc@uc.cl.

Daniela Aranis. Socióloga. Investigadora del Centro de Estudios Interculturales e Indígenas, Pontificia Universidad Católica de Chile. Email: dparanis@uc.cl. 
40 por ciento. La urbanización ha estado siempre asociada a migración y desplazamientos internos desde el campo hacia la ciudad, pero también deben considerarse procesos más recientes de etnificación urbana (Imilan 2014), a través de los cuales una población con residencia urbana de antigua data toma conciencia de una identidad étnica que estuvo latente por mucho tiempo.

La evidencia migratoria para el caso mapuche es muy amplia, pero está poco cuantificada (Bello 2002). La hipótesis convencional sobre la migración mapuche sostuvo que provenía de la estrechez de la economía reduccional $(6,1$ hectáreas promedio por persona que fueron reduciéndose por traspaso y usurpación de tierras en el correr del siglo pasado). Esta hipótesis ha alimentado toda la política de devolución de tierras y de aumento de la extensión de tierra indígena de las últimas décadas. El programa de consolidación de la propiedad privada (más que de ampliación de la superficie) que se implementó bajo la dictadura no tuvo ningún impacto visible sobre la radicación indígena. Tampoco existe ninguna evaluación seria de las políticas de compra y traspaso de tierras indígenas de las últimas décadas, aunque debe destacarse, en el volumen reseñado, el análisis crítico que realiza Sebastián Donoso sobre la política de compra de predios en conflicto (Donoso 2017). Existe alguna evidencia, sin embargo, respecto a que los flujos migratorios actuales no están operando por expulsión, sino por atracción que la población rural siente por las ciudades, donde se concentran abrumadoramente mejores posibilidades de empleo y educación. Los jóvenes no se quedan en el campo aun cuando hubiere algunas posibilidades de progreso. Las alternativas que existen frente a la economía reduccional son mucho más amplias que en el pasado — donde no había prácticamente ninguna - y casi todas ellas ofrecen una mejor perspectiva de vida. Hace veinte años, por ejemplo, la proporción de mapuches jóvenes que vivía en el ámbito urbano en La Araucanía (21 por ciento) no se distinguía de los que vivían en el ámbito rural (20 por ciento), mientras que hoy existe una diferencia de 8 puntos porcentuales: 24 por ciento en la zona urbana y 16 en la rural, según estimaciones de la Casen (2015). El progreso educativo de los últimos años hace lo suyo: es poco probable que un joven mapuche con educación superior vuelva al campo. También hace veinte años, el 10 por ciento de mapuches que vivían en la ciudad poseían educación terciaria, mientras que hoy la proporción 
aumentó a 26 por ciento, al tiempo que las zonas rurales retienen solamente al 9 por ciento de población mapuche con educación superior.

El declive de la economía reduccional va de la mano con una tendencia hacia la disminución y envejecimiento de la población rural. En las últimas décadas, la edad promedio de los hogares mapuche ha aumentado de 33 a 41 años y el tamaño promedio de los hogares rurales descendió de 4,4 a 3,4 personas, aunque es posible que no haya nada específicamente indígena en estas cifras. El campo pierde aceleradamente población en edad de trabajar y la proporción de jefes de hogar de edad avanzada ha aumentado en las últimas décadas. Existe evidencia de que la superficie sembrada en tierras indígenas ha caído en el último tiempo y que la agricultura comercial se ha recogido todavía mucho más que lo que ha sido habitual en la economía reduccional indígena (Bengoa y Valenzuela 1981), que nunca pudo salir realmente del umbral de subsistencia. Las nuevas oportunidades de empleo y las transferencias de subsidios monetarios se han convertido, asimismo, en alternativas frente a una agricultura de subsistencia de bajo rendimiento económico. A diferencia de antaño, se puede conseguir trabajo remunerado en aldeas y ciudades aledañas al campo, que no requieren de ningún esfuerzo inmigratorio permanente ni desplazamientos hacia localidades remotas, como sucedía con la temporada de la fruta en la Zona Central, que recibió por años mucho trabajador mapuche, tanto como la albañilería en madera, que también atrajo — y continúa haciéndolo- migrantes temporales de origen mapuche hacia el centro del país. Los subsidios también se han instalado como una fuente significativa de ingresos monetarios en el campo mapuche. Cerda (2017), en este mismo volumen, llama la atención sobre los problemas de focalización de los subsidios que terminan por favorecer a población no pobre por encima de aquella pobre o indigente. Sus datos muestran que mapuches y no mapuches reciben montos de subsidio per cápita relativamente similares; sin embargo, la distribución de estos subsidios en el continuo urbano-rural es muy diferente. El 36 por ciento de los hogares en zonas rurales tiene el Subsidio Único Familiar, mientras que sólo el 17 por ciento de los hogares en zona urbana posee este subsidio. Además, un tercio de los hogares rurales tiene un miembro del hogar que recibe la Pensión Básica Solidaria de vejez o invalidez, 17 puntos porcentuales más que en los hogares urbanos. Esta drástica diferencia en la Pensión Básica Solidaria 
muestra el proceso de envejecimiento que está presentando la población rural mapuche.

Los temores acerca de la capacidad que tiene la economía mapuche de albergar y retener población indígena significativa, que han atravesado todo el período reduccional, pueden verse redoblados en la actualidad. La migración por razones educativas es quizás la fuente principal de desplazamientos, sobre todo con una masificación de la educación superior que obliga a trasladarse a grandes ciudades. También hace lo propio el cierre casi definitivo de las posibilidades de generar una agricultura comercial de cierta consideración en suelo mapuche, así como de producir una clase media indígena con base rural. Por contrapartida, debe advertirse acerca de las posibilidades de educación y empleo que ofrece la economía regional de La Araucanía, que modera la migración de antaño, casi toda orientada hacia la Región Metropolitana, que fue siempre más remota y, por ende, más definitiva e irreversible.

La migración por expulsión genera vínculos y en ocasiones la decidida intención de volver, mientras que aquella que sucede por atracción es más descuidada respecto del origen. El patrón de migración urbana está muy bien descrito por Imilan, como una "experiencia migratoria de tipo individual, apoyada en redes y organizaciones de base mapuche, pero de limitada extensión y en pocas oportunidades con vínculos con las comunidades de origen" (Imilan 2017, 87). Originalmente, los migrantes carecían de vivienda y entraban en la ciudad a través de oficios que les proporcionaban algún techo, como la panadería, la policía o la servidumbre doméstica. No se constituyeron barrios mapuches, ni hubo señales de diferenciación étnica en la ciudad. El patrón inmigratorio estuvo, a su vez, ligado a dos procesos de asimilación muy profundos: la desaparición de la lengua y la expansión del matrimonio mixto.

El deterioro de la lengua está descrito por Zúñiga y Olate (2017) en este mismo libro. El declive en la competencia activa en la lengua (habla mapuzugun aunque sea peor que el castellano) en los últimos diez años, según sus datos, es considerable: desde el 40 hasta el 25 por ciento en el área rural y desde el 13 hasta el 7 por ciento en el área urbana, aunque estos datos pueden estar afectados por el incremento de la identificación indígena en este mismo período, que seguramente se acrecienta por el lado de los que tienen menos dominio de la lengua. ¿Por qué sucede esto, sin embargo, también en áreas rurales, donde es 
poco probable que se haya producido una inflación de identificación indígena? Una posible razón de esta disminución es la radicación de la lengua en los mayores y los efectos del reemplazo generacional. Efectivamente, a medida que aumenta la edad, se incrementa la proporción de mapuches que hablan mapuzugun mejor o igual que el castellano, tanto en el ámbito urbano como rural (ELRI 2016; PNUD 2013). La diferencia es a tal punto contundente que solamente el 6 por ciento de los jóvenes mapuche entre 18 y 29 años entiende la lengua con facilidad, mientras que el 38 por ciento de los adultos mayores de 60 años comprenden la lengua. También llama la atención una caída de la participación frecuente en la ceremonia del nguillatun reportada en Imilan, desde el 23 hasta el 15 por ciento en el área rural, mientras que en el área urbana se mantiene en apenas 3 ciento. Los datos de la encuesta CEP muestran que la pervivencia de la lengua y de la cultura ancestral están radicadas casi enteramente en zonas rurales, y que incluso allí el alcance de estas expresiones de identidad es limitado. Además, éstas se encuentran en franco deterioro. Si la competencia activa en la lengua en el Wallmapu no alcanza a más del 25 por ciento de los mapuches, la participación activa en la ritualidad indígena bordearía una cifra similar según sea el criterio de medición. La capacidad de reproducir la lengua y la cultura se encuentra, por su parte, en un punto crítico. Según Zúñiga y Olate (2017), apenas el 14 por ciento de los mapuches en la zona rural habla mapuzugun con sus hijos pequeños; es decir, la transmisión familiar de la lengua está prácticamente interrumpida, lo que constituye el indicio más desfavorable respecto de las posibilidades de supervivencia de una lengua. Prácticamente toda la transmisión de la lengua y la cultura explícita se hace a través de instituciones y organizaciones secundarias, casi enteramente desprendida del soporte familiar. Estas dificultades de transmisión familiar pueden acentuarse con el envejecimiento poblacional en el campo, pero también con la prevalencia y aceptación del matrimonio mixto en el mundo mapuche.

Los datos censales disponibles señalan que alrededor de la mitad de los mapuches tiene una pareja no mapuche, lo que muestra una amplia apertura exogámica, que se acrecienta con la residencia urbana y el nivel de escolaridad, dos indicadores en creciente progreso. Según cifras del PNUD (2013), el 66 por ciento de los mapuches encuestados 
que vive en zonas urbanas tiene una pareja no mapuche, una cifra que desciende a 31 por ciento en zonas rurales (también ELRI 2016 ofrece una estadística similar). Un hallazgo relevante remite a la relación entre dominio de la lengua y matrimonio mixto. Aproximadamente, un tercio de los mapuches que están casados con mapuches entiende con facilidad la lengua, mientras que esto sucede sólo en el 11 por ciento de los que tienen pareja no mapuche (PNUD 2013). La probabilidad de transmitir la lengua en el seno de una pareja mixta disminuye considerablemente.

La aceptación del matrimonio mixto (que un hijo o hija se case con un no mapuche) ha sido muy amplia entre los mapuches, no ha variado en la última década y es prácticamente igual en áreas rurales como urbanas. Según Course (2017), en la sociedad rural tener padre y madre mapuche es un signo de mapuchidad que remite al fenotipo mapuche ("parecen mapuches") y a la competencia lingüística (hablan mapuzugun). El matrimonio mixto champurrea al hijo, aunque su pertenencia a una comunidad indígena puede sostener definitivamente su identidad mapuche, a pesar de que subsiste la convicción de que el lado no mapuche (o winka) tiende a prevalecer (Course 2017). La particularidad del matrimonio mixto radica en que no interrumpe la identificación de los hijos como mapuches, según lo establece la hipótesis convencional de la asimilación, que indica que en parejas mixtas prevalece la identidad del grupo mayoritario. Utilizando datos censales, Unzueta y Valenzuela (2015) mostraron que alrededor de la mitad de los padres en pareja mixta identifican a sus hijos como mapuches y la otra mitad como no mapuches, descartando que exista alguna regla tajante en la clasificación de los hijos de tales parejas. También la experiencia urbana está relacionada con la ampliación definitiva de los contactos intergrupales. González y Mackenna (2017) han estudiado en este mismo volumen las redes de contacto en la población mapuche y observan diferencias entre población urbana y rural: "La mayoría de los confidentes de los mapuches urbanos son no mapuches" (González y Mackenna 2017, 53). El contacto intergrupal influye en la probabilidad de identificarse con el exogrupo, específicamente en la situación de que un mapuche se identifique al mismo tiempo como chileno, y no exclusivamente como mapuche, algo que sí sucede con mayor frecuencia en áreas rurales de bajo contacto intergrupal. 
A pesar de todos estos signos inequívocos de menoscabo en la identidad étnica, la imagen del Wallmapu sigue viva en la conciencia mapuche. La encuesta CEP reporta de manera abundante la nostalgia por la sociedad rural, aunque en esto no hay algo exclusivamente indígena, sino una tendencia que atraviesa a toda la sociedad chilena, probablemente hastiada de los rigores de la vida urbana. A pesar de la evidencia, la mayor parte - incluyendo mapuches y no mapuches urbanos - considera que se vive mejor en el campo que en la ciudad. Cerda (2017), en este mismo volumen, ofrece datos que muestran que los ingresos ocupacionales de la población mapuche de la Región de La Araucanía son en alrededor del 23 por ciento menores que los de los mapuches que viven en el resto del país. Por otra parte, la encuesta indica que a los mapuches que viven en el campo no les gustaría que sus hijos se fueran a la ciudad, al tiempo que aquellos que viven en la ciudad desearían — sólo algo menos insistentemente- que sus hijos volvieran al campo (en una medida que sólo en este último caso favorece claramente a mapuches respecto de no mapuches). Volver al campo, por ejemplo, es algo que motiva a tres de cada cuatro mapuches urbanos tratándose de sí mismos, y todavía dos tercios lo consideran un horizonte deseable para sus hijos. Visto desde el mundo rural, sin embargo, muy pocos mapuches confían en que el campo pueda retener (y todavía menos acoger) a los jóvenes, pues piensan que terminarán inevitablemente yéndose, mientras que la ciudad es percibida casi inequívocamente como la ruina de la cultura, una desazón que ha atravesado el mundo rural mapuche durante toda la época reduccional.

La referencia al Wallmapu puede observarse más de cerca a través de lo que se denomina sentido del lugar, un lugar con el que alguien se siente identificado o con el que guarda particularmente apego. El sentido del lugar remite usualmente al lugar de origen (en mapuche, tuwün), pero puede abarcar también la residencia habitual, e incluso el lugar de solaz o veraneo como sucede con muchos de quienes habitan en grandes ciudades a la hora de identificar un espacio de apego. En el caso de la sociedad rural mapuche, el tuwün es un elemento de diferenciación entre el mapuche y el winka: el mapuche tiene un lugar de origen, mientras que el winka vive desarraigado (Di Giminiani 2012). Asimismo, el tuwün determina una manera de ser en el mundo que distingue a un mapuche de otro mapuche en razón justamente de su procedencia. El 
tuwün debe distinguirse del Wallmapu, es decir, del territorio histórico donde se desarrolló la cultura mapuche y que contiene la memoria de su lucha histórica contra el colonizador. Un estudio reciente sobre el sentido del lugar (ELRI 2016) ha mostrado que la proporción que conserva apego a algún lugar es algo mayor entre mapuches (50 por ciento) que entre no mapuches (40 por ciento). En la Región Metropolitana, específicamente, el 44 por ciento de los mapuches posee un sentido del lugar, mientras que solamente el 25 por ciento de los no mapuches identifica alguno.

¿Dónde se encuentra ese lugar de apego? Los datos indican que éste es abrumadoramente rural, cualquiera sea la población de referencia, confirmando que las localidades rurales suscitan muchísimo más apego que las ciudades. En el caso de la población mapuche se ha podido determinar que el 36 por ciento menciona algún lugar de apego en el Wallmapu, una cifra que alcanza al 28 por ciento de los mapuches que residen en la Región Metropolitana. Alrededor de uno de cada cuatro mapuches que ha migrado hacia la ciudad (al menos hacia la Capital Metropolitana que ofrece el modelo convencional de inmigración) conservaría una referencia simbólica al territorio original. La mayor parte de estos mapuches confirma que el lugar con el cual se sienten identificados (entre aquellos que mencionan un lugar de apego) es un sitio ancestral, lo que indicaría que uno de cada cinco inmigrantes mapuches conserva el sentido del tuwün. ¿Se trata solamente de una nostalgia por el mundo rural desconectada de todo contacto efectivo? El mismo estudio (ELRI 2016) ha mostrado que alrededor del 60 por ciento de los mapuches que actualmente residen en la Región Metropolitana nunca han vivido ni tienen contacto alguno con una comunidad indígena tradicional y aparecen enteramente desconectados con el Wallmapu. La otra parte, en cambio, mantiene alguna clase de contacto, sea porque ha vivido alguna vez en una comunidad y puede considerarse un inmigrante reciente o de primera generación, sea porque tiene familiares cercanos o sea porque incluso retiene algún derecho de propiedad en una comunidad indígena. Ahora bien, quienes identifican algún lugar del Wallmapu como propio son generalmente los mismos que tienen contacto con este lugar.

En la sociedad rural, la "mapuchidad" (en particular la diferencia entre mapuche y winka) está definida por la referencia a la tierra como 
algo enraizado (Di Giminiani 2012), que incluye sobre todo al tuwün como lugar ancestral. La mapuchidad se afirma en la continuidad entre la tierra y la gente (González 2016), lo que a su vez se sostiene en la descendencia (tener padre y madre mapuche), pero también en la residencia: es más mapuche quien vive en el campo respecto de quien lo hace en la ciudad. En el plano de la cultura, la mapuchidad se afirma en la lengua y en algunos pocos ritos que se conservan menos: nguillatun (ritual de fertilidad mapuche) y palín (deporte tradicional), y casi nada tratándose de los ritos de pasaje, como el lakutün (aproximadamente un bautizo mapuche) y el eluwün (funeral mapuche). Los datos entregados por la encuesta CEP confirman la importancia que se otorga a la lengua como elemento indispensable para mantener la cultura mapuche (primera mención, con 56 por ciento entre mapuches rurales, y una proporción semejante entre mapuches urbanos), pero también que no se otorga casi ninguna importancia a la participación en ceremonias y ritos ancestrales, y en lo que genéricamente se podría llamar "religión” (quinto lugar de precedencia, con alrededor del 15 por ciento de las menciones, también en el campo mapuche).

El lugar de la religión lo ocupa, en cambio, la disposición a conocer la historia del pueblo mapuche (segunda mención en importancia, alrededor de un tercio de menciones con acento entre mapuches rurales). El sentido de comunidad se puede actualizar a través de ritos de naturaleza religiosa (en el sentido clásico que le otorga Durkheim), pero también a través de la memoria, generalmente la memoria oral, que transmite de generación en generación los mitos de fundación o una determinada épica histórica, en lo que Hervieu-Léger (2005) llama el "hilo de la memoria" para definir justamente el hecho religioso. La historia de la resistencia secular del pueblo mapuche contra la colonización de su territorio y luego la expoliación de tierras puede jugar un rol preponderante en esta memoria, que actualmente se expresa también como memoria escrita a través de una intelectualidad pro indígena o derechamente indígena, en lo que se ha llamado "emergencia indígena" (Bengoa 2000). ¿Puede la memoria subsistir fuera de la actualización que le proporcionan las ceremonias y los ritos, es decir, como memoria puramente textual? Algunos autores sostienen que la mapuchidad se sostiene ontológicamente a través del vínculo con la tierra (González 2016), entendida sobre todo como tuwün más que como Wallmapu. 
Según los resultados de la encuesta CEP, vivir del trabajo de la tierra o en una comunidad indígena tradicional constituyen el tercer grupo de elementos más mencionados para afirmar la cultura mapuche, lo que entrega finalmente una tríada formada por lengua, memoria y tierra como base de la mapuchidad. La descendencia no juega un rol principal, al menos si se considera que casarse entre mapuches apenas recibe alguna mención, lo que confirma la amplia aceptación del matrimonio mixto, a pesar de sus consecuencias devastadoras sobre la transmisión de la lengua. En el otro extremo de la sangre, el reconocimiento constitucional de la diferencia étnica tampoco recibe ninguna mención relevante, lo que muestra que el soporte institucional de la cultura - aunque deseable - no juega un rol decisivo en la determinación de la identidad étnica, algo que puede cambiar, sin embargo, en la sociedad urbana a medida que se institucionalizan políticas de reconocimiento y discriminación positiva que movilizan mucha conciencia mapuche. La mapuchidad puede llegar a convertirse en una definición institucional, al punto de que la identidad se sustituya por la autoidentificación vaciada de toda sustancia cultural.

Las religiones establecidas quedan completamente aparte en la definición de la mapuchidad. La particularidad de la sociedad rural mapuche es la abultada proporción de mapuches que se identifican como evangélicos (38 por ciento en la encuesta CEP, el doble del promedio nacional y casi el mismo porcentaje que tiene la identificación católica). En áreas urbanas, la proporción de evangélicos retorna al promedio que corresponde a la población de menor nivel socio-económico. La identificación católica nunca ha ofrecido fricciones con la identidad étnica. El catolicismo sustituyó los antiguos ritos de pasaje (lakutün y eluwün) y se introdujo, por ende, en el tuwün como comunidad de residencia, descendencia y pertenencia en la comunidad (Di Giminiani 2012). El catolicismo careció siempre de un rito agrario y dejó intacto el nguillatun como ofrenda y rogativa de fertilidad de la tierra. La singularidad de la evangelización capuchina en la zona mapuche es la ausencia de grandes santuarios en todo el Wallmapu y la debilidad consiguiente en la devoción mariana con su énfasis en la cura milagrosa de las imágenes y la formación de una comunidad festiva. El catolicismo pudo implantarse en el tuwün, pero no logró trascender la comunidad de descendencia ni alcanzó a constituir una comunidad ritual por encima de la comunidad de origen. 
El origen común se ha seguido afirmando invariablemente por una referencia a la tierra (mapuche $=$ gente de la tierra), que se actualiza en un rito fundamentalmente agrario. Course define la diferencia entre católicos y evangélicos de esta manera: "Mientras ser católico significa que uno bebe alcohol y participa en eventos sociales como el palín, nguillatun y el eluwün, ser evangélico implica que uno se abstiene de participar en cualquiera de estas actividades" (Course 2017, 66). La renuencia evangélica a seguir las "maneras de la tierra" contrasta con su florecimiento en suelo mapuche. La evidencia indica, sin embargo, que la identificación mapuche no se resiente con la condición de evangélico, y debe afirmarse enfáticamente que no hay incompatibilidad entre ser mapuche y ser evangélico. El pentecostalismo penetra sobre todo a través de la eficacia de su rito de sanación (“oración de ungimiento"), que tiende a sustituir al de la machi, que en muchas comunidades ha desaparecido (también documentado por la encuesta CEP: el recurso a la machi ha disminuido de 25 a 16 por ciento en zona rural en apenas diez años). Según González (2016), ambas prácticas — sanación evangélica y machi- remiten a la posesión espiritual como causa eficiente de la enfermedad, lo que puede resolverse a través de la unción profética o del éxtasis chamánico. Course menciona el caso de quienes van y vienen entre el evangelismo y el catolicismo con el relato de Marta - "fui a esos evangélicos cuando estaba enferma" (Course 2017, 66)_, que retorna cuando le prohíben celebrar con alcohol y, por ende, participar en actividades comunitarias. La ausencia de un catolicismo mariano impide establecer un recurso eficaz de sanación ("milagro"), que queda en manos del soporte que puede ofrecer la machi o la comunidad terapéutica del evangelismo.

Ahora bien, el conjunto de estos comentarios apunta en una misma dirección: mostrar las posibilidades de la identificación mapuche en un contexto de declive de la economía rural y de una rápida urbanización. Algunos autores han sugerido que, fuera de su morada cultural, la identidad indígena sólo puede sostenerse políticamente en la conciencia explícita de sí misma que puede adquirir un determinado grupo (Mascareño 2007). Algunos procesos de etnificación urbana pueden estudiarse de esta manera, en especial entre jóvenes de segunda generación, completamente desconectados de todo contacto efectivo y de cualquier referencia simbólica al Wallmapu, y que, no obstante, adquieren conciencia 
de su condición étnica, generalmente, a través del reconocimiento (más que del desconocimiento) de terceros. La revitalización de la identidad indígena, que se expresa en reconocimiento político y en beneficios sociales, juega un rol considerable, mucho más amplio quizás que la discriminación, que suele ser de bajo calibre y poco reportada en todas las encuestas. Es diferente cobrar conciencia de la propia identidad cuando esta última está socialmente enaltecida en lugar de deteriorada. ¿Cuánto y cómo puede sostenerse, sin embargo, la identidad mapuche en tales condiciones de desarraigo? Lo más inquietante es el declive de la sociedad rural y el deterioro del tuwün, es decir, la incapacidad de afirmar el vínculo con la tierra a través de la pertenencia (por efectos de la migración) y de la descendencia (por disolución de las relaciones de parentesco y afinidad con aquellos que viven en las comunidades). El envejecimiento poblacional en el campo corta la trama de la transmisión cultural (en particular de la lengua), al tiempo que desaparecen las maneras de la tierra en un contexto de abandono progresivo de las labores del campo y de la economía agrícola. El tuwün se mantiene como una referencia viva para quienes habitan en las comunidades, pero lo es mucho menos para quienes emigran hacia las ciudades. Casi todo el proceso de etnificación urbana no tiene ya como referencia al tuwün. Lo que queda en pie es el Wallmapu, que ha adquirido cada vez mayor importancia en la conciencia mapuche, ya no como referencia al origen, sino como actualización de una memoria histórica de la unidad del pueblo en torno a la defensa de un territorio expoliado.

\section{REFERENCIAS}

Aninat I., V. Figueroa \& R. González, eds. 2017. El pueblo mapuche en el siglo XXI. Propuestas para un nuevo entendimiento entre culturas en Chile Santiago: Centro de Estudios Públicos.

Bello, A. 2002. "Migración, Identidad y Comunidad Mapuche en Chile: Entre utopismos y realidades". Asuntos Indígenas 3-4: 40-47.

Bengoa, J. 2000. Emergencia indígena en América Latina. Santiago: Fondo de Cultura Económica.

Bengoa, J. \& E. Valenzuela. 1981. Economía mapuche. Pobreza y subsistencia en la sociedad mapuche contemporánea. Santiago: PAS.

Casen. 2015. Encuesta de caracterización socioeconómica nacional. Santiago: Ministerio de Desarrollo Social. 
Centro de Estudios Públicos. 2016. Encuesta "Los mapuches rurales y urbanos hoy". Marzo-mayo. https://cepchile.cl/cep/site/artic/20160607/ asocfile/20160607195127/encuestacep_mapuche_marzo_mayo2016.pdf

Cerda, R. 2017. "Situación socio-económica reciente de los mapuches: 2009-2015". En Aninat, Figueroa \& González 2017, 405-434.

Course, M. 2017. Mapuche ñi mongen. Persona y sociedad en la vida mapuche rural. Santiago: Pehuén.

Di Giminiani, P. 2012. Tierras ancestrales, disputas contemporáneas. Pertenencia y demandas territoriales en la sociedad mapuche rural. Santiago: Ediciones Universidad Católica de Chile.

Donoso, S. 2017. "Compra de predios en conflicto. Análisis crítico y una propuesta". En Aninat, Figueroa \& González 2017, 293-342.

Durston, J. 2013. Pueblos originarios y sociedad nacional en Chile. La interculturalidad en las prácticas sociales. Santiago: Programa de las Naciones Unidas para el Desarrollo.

ELRI. 2016. Estudio longitudinal de relaciones interculturales. Centro de Estudios Interculturales e Indígenas. PUC, UDP, Universidad Academia de Humanismo Cristiano \& Midap.

González, M. 2016. Los mapuche y sus otros. Persona, alteridad y sociedad en el sur de Chile. Santiago: Editorial Universitaria.

González, R. \& B. Mackenna. 2017. "Relaciones interculturales entre mapuches y no mapuches: desigualdad, segregación y autonomía”. En Aninat, Figueroa \& González 2017, 45-78.

Hervieu-Léger, D. 2005. La religión, hilo de la memoria. Barcelona: Herder.

Imilan, W. 2014. "Experiencia warriache: Espacios, performances e identidades mapuche en Santiago". En Poblaciones en movimiento. Etnificación de la ciudad, redes e integración, editado por I. Walter. Santiago: Ediciones Alberto Hurtado.

Imilan, W. 2017. "Ser mapuche en la ciudad: Perspectivas sobre migración". En Aninat, Figueroa \& González 2017, 79-110.

Mascareño, A. 2007. "Sociología de la cultura: La deconstrucción de lo mapuche". Estudios Públicos 105: 61-112.

PNUD. 2013. Primera encuesta relaciones interculturales, 2012. Programa de las Naciones Unidas para el Desarrollo. http://www.onu.cl/es/wpcontent/uploads/2013/10/Primera-Encuesta-de-Relaciones-InterculturalesPNUD-2013.pdf

Unzueta, B. \& E. Valenzuela. 2015. "Parental Transmission of Ethnic Identification in Mixed Couples in Latin America: The Mapuche Case". Ethnic and Racial Studies 38 (12): 2090-2107.

Zúñiga, F. \& A. Olate. 2017. "El estado de la lengua mapuche, diez años después". En Aninat, Figueroa \& González 2017, 343-374. EP 
